\title{
Adolescent pelvic chondrosarcoma, surgical treatment, and unusual reconstruction with pedestal conic cup $\left(\mathrm{LUMiC}^{\circledR}\right)$ : A case report
}

\author{
Tahsin Sami Çolak, MD (i), Ahmet Fevzi Kekeç, MD®D \\ Department of Orthopedics and Traumatology, Necmettin Erbakan University, Meram Faculty of Medicine, Konya, Turkey
}

Chondrosarcoma is a malignant primary bone tumor originating from chondrocytes that produce cartilage. ${ }^{[1,2]}$ The prognosis and behavior of chondrosarcoma can range from slowly growing and non-metastatic tumor to very aggressive pattern and metastasis ${ }^{[3]}$ Clinical behavior is generally consistent with the histological structure of the lesion. Histologically, three subgroups are distinguished by their characteristics such as cell atypia and cellularity (grades 1, 2, and 3). ${ }^{[4-6]}$ Some subtypes are also described (secondary, dedifferentiated, clear cell, mesenchymal, periosteal). It is more common in male sex aged over 40 years and it mostly occurs in the scapula, proximal humerus, femur, pelvic girdle, knee, and spine. ${ }^{[5]}$ The most common complaints of patients are pain and mass. Because of the resistance to chemotherapy and radiotherapy, it is frequently treated by surgery. ${ }^{[7,8]}$

Received: March 18, 2020

Accepted: May 04, 2020

Published online: September 11, 2020

Correspondence: Tahsin Sami Çolak, MD. Necmettin Erbakan Üniversitesi Meram Tıp Fakültesi, Ortopedi ve Travmatoloji Anabilim Dalı, 42080 Meram, Konya, Türkiye.

E-mail: drtahsincolak@gmail.com

Doi: $10.5606 /$ ehc. 2020.74884

Citation: Colak TS, Kekeç AF. Adolescent pelvic chondrosarcoma, surgical treatment, and unusual reconstruction with pedestal conic cup (LUMiC $\left.{ }^{\circledR}\right)$ : A casereport. JtDisRelatSurg2020;31(3):648-652.

(2020 All right reserved by the Turkish Joint Diseases Foundation

This is an open access article under the terms of the Creative Commons Attribution-NonCommercial License, which permits use, distribution and reproduction in any medium, provided the original work is properly cited and is not used for commercial purposes (http://creativecommons.org/licenses/by-nc/4.0/).

\section{ABSTRACT}

An 18-year-old male patient was diagnosed pelvic chondrosarcoma histopathologically. Hip joint involvement was detected. No metastasis or neurovascular invasion was seen. Type I+II pelvic resection and hip reconstruction were planned with pedestal cup (LUMiC®) and proximal femur tumor prosthesis. Surgery was performed in lateral decubitus position with extensive triradiate incision. Pelvic wide resection was performed. At the second year of follow-up, implant failure was detected and patient was revised with same pedestal cup. Axial stability was supported by a L5 screw and connector from L5 vertebrae to LUMiC® prosthesis. Except the implant failure, no oncological complication or infection was observed during the final $36^{\text {th }}$ month follow-up.

Keywords: Adolescent, chondrosarcoma, hemipelvectomy.

The aim of this study is to show that a rare case of chondrosarcoma seen in adolescent pelvis can reach a satisfactory functional outcome by reconstruction with LUMiC $^{\circledast}$ prosthesis and spinopelvic fixation with polyaxial screws as a new surgical technique when there is no sufficient bone stock after pelvic resections. ${ }^{[9]}$

\section{CASE REPORT}

An 18-year-old male patient was admitted to our clinic with pain and limping on the right hip, and a mass was detected at the right iliac wing on physical examination. The patient underwent pelvic radiography, pelvic computed tomography, and pelvic magnetic resonance imaging (MRI). On MRI, tumoral tissues originating from destroyed cortex of the right iliac wing was extending to the right sacroiliac junction adjacent to the iliac crest accompanied by the soft tissue component. Moreover, hip joint involvement was also detected (Figure 1a-c). No metastasis or neurovascular 

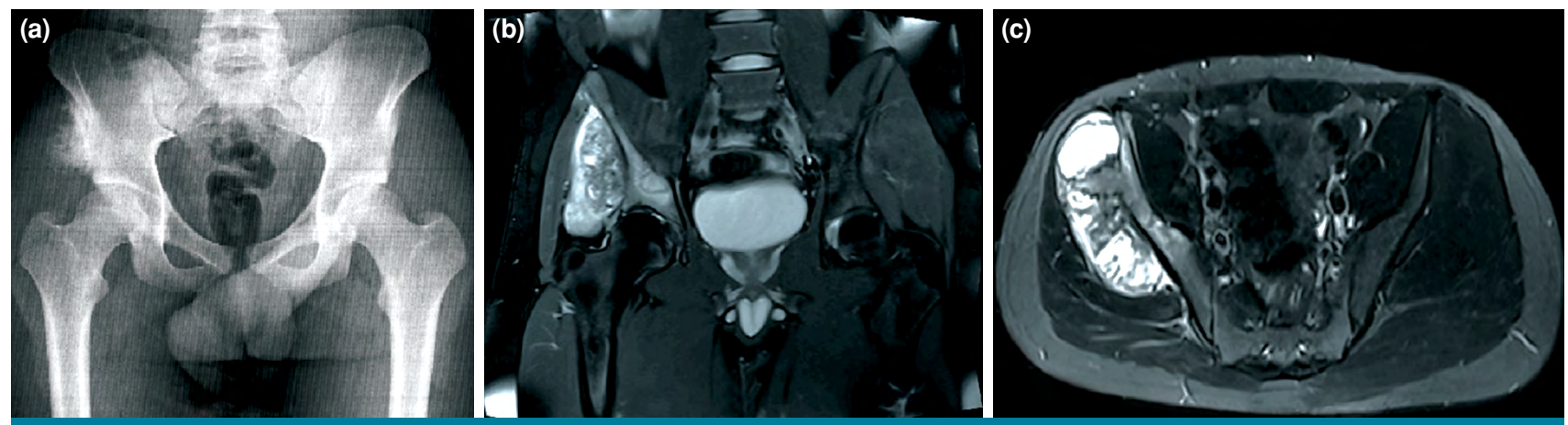

FIGURE 1. (a) In anteroposterior pelvic X-ray, there is an exophytic lesion containing a chondrogenic matrix that grows from right iliac wing. (b) In coronal T2 fat-suppressed sequences, an exophytic growing soft tissue mass from right iliac bone is invading lateral capsule of hip joint. (c) In axial T2 fat-suppressed sequences, T2 increased signal intensity in right iliac bone extends through bone marrow and subchondral area of sacroiliac joint while sacroiliac joint involvement is absent.

invasion was seen. Tru-cut biopsy was performed and chondrosarcoma (grade 2) was diagnosed histopathologically. Proximal femur modular tumor prosthesis and pedestal conic cup (MUTARS ${ }^{\circledR}$ LUMiC $^{\circledR}$ acetabular implantcast, Buxtehude, Germany) were planned for joint and bone reconstruction after type I+II resection which was described by Enneking. ${ }^{[10-15]}$ A written informed consent was obtained from the patient.

Surgery was performed in the lateral decubitus position under general anesthesia. " $\mathrm{T}$ " (extensive triradiate) incision was used to facilitate access to the posterior and anterior anatomical structures, which could also exclude the biopsy tract (Figure 2a). Wide resection was achieved by performing type I+II internal hemipelvectomy. For reconstruction, cemented pedestal conic cup $\left(\mathrm{LUMiC}^{\circledR}\right)$ was used through ala of sacrum and L5 spine. To avoid any length discrepancy at the lower extremity, the joint level was raised and the joint was reconstructed with a proximal femur modular tumor resection prosthesis (Figure $2 \mathrm{~b}, \mathrm{c}$ ). No intraoperative complication was encountered.

No complications were seen clinically and radiologically in early postoperative period (Figure 3a, b). Non-weight-bearing mobilization was allowed at the end of first week and patient was discharged on postoperative $21^{\text {st }}$ day. Partial weight bearing was allowed at postoperative second month. Musculoskeletal tumor society (MSTS) scores were

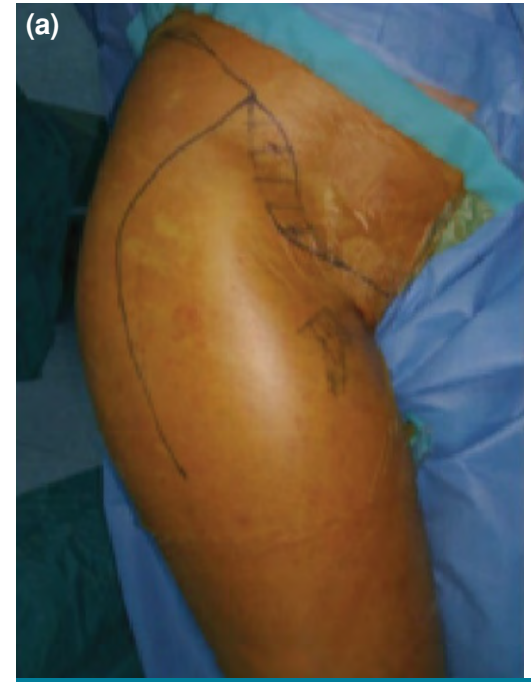

FIGURE 2. (a) Preoperative wound planning. prosthesis. (c) Postoperative wound closure.
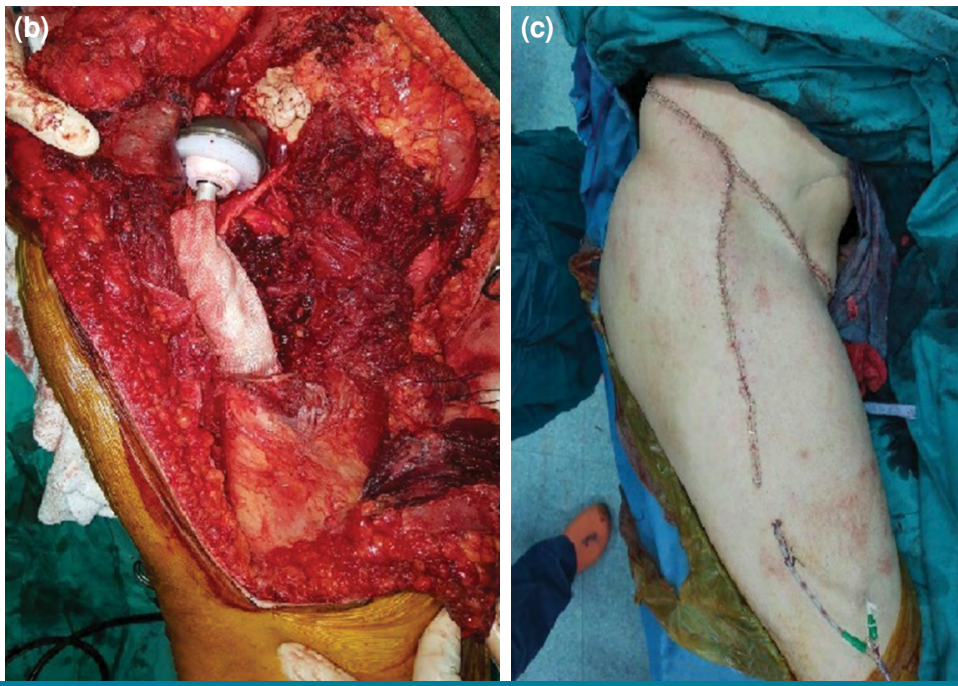
(b) Intraoperative tumor resection and reconstruction with 

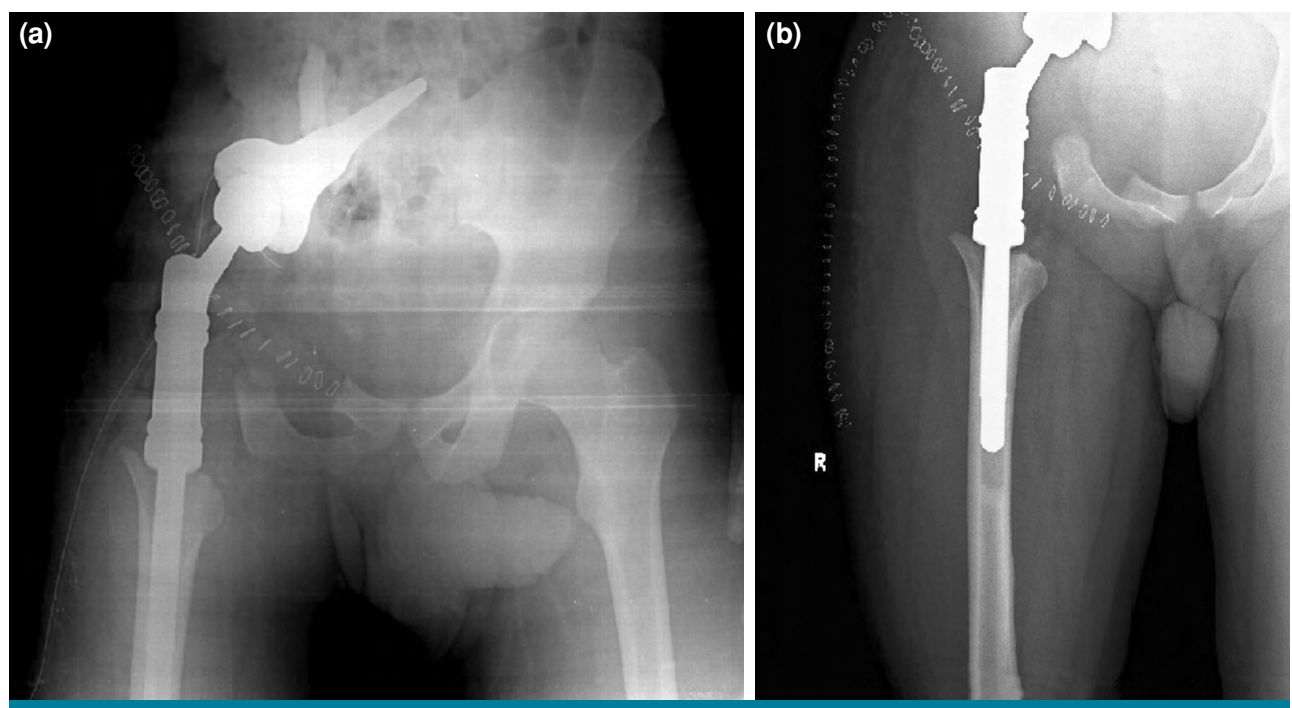

FIGURE 3. (a, b) Early postoperative anteroposterior X-rays (placement of pedestal cup, LUMiC ${ }^{\circledR}$ through sacrum and L5 vertebra). Balanced lower extremity length after reconstruction.

$23(66 \%)$ at sixth and $29(83 \%)$ at $12^{\text {th }}$ months of control visit. ${ }^{[16]}$

At the postoperative $23^{\text {rd }}$ month, the patient applied to our clinic with acute onset of increased limping and hip pain after a motorcycle accident. Implant failure on the $\mathrm{LUMiC}^{\circledR}$ and limb discrepancy were detected and the decision was established for revision (Figure 4a). In the second operation, previous incision was used and extended proximally for anterior instrumentation of L5 corpus. Hip joint instability and pathological movement of LUMiC $^{\circledR}$ stem were detected (Figure 5a). LUMiC ${ }^{\circledast}$ and cements were removed and signs of infection were not detected. Then, sacrum and L5 vertebrae corpus were reamirized together and $\mathrm{LUMiC}^{\circledR}$ stem was placed with cement into the ala of sacrum and L5 spine as the previous operation. Additionally, axial stability of $\mathrm{LUMiC}^{\circledR}$ prosthesis was supported by a L5 polyaxial corpus screw and lateral connector rod from L5 vertebrae to LUMiC $^{\circledR}$ prosthesis (Figures $4 \mathrm{~b}$ and $5 \mathrm{~b}$ ). Then, two Kirschner wires were placed to ala of sacrum and all implants were augmented by antibiotic loaded cement to support the stability of our reconstruction (Figure 5c).

Wounds were closed properly and suction drains were placed. No complication was seen in the early postoperative period. Non-weight-bearing mobilization was allowed on postoperative second day and patient was discharged at the end of the first week. MSTS score was $23(66 \%)$ at the $12^{\text {th }}$ month after the second operation.
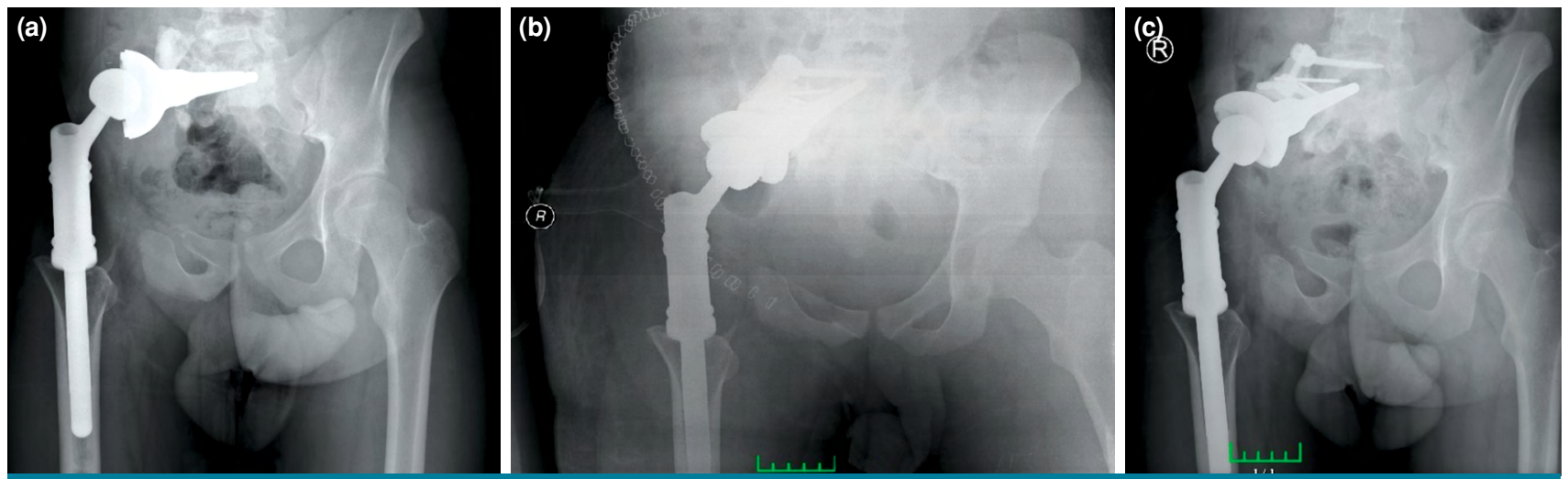

FIGURE 4. (a) Postoperative $23^{\text {rd }}$ month anteroposterior X-ray shows failure of LUMiC ${ }^{\circledR}$ after motorcycle accident. (b) After final operation, early anteroposterior pelvic X-ray (placement of LUMiC ${ }^{\circledR}$ and L5 corpus screw and rods). (c) Control anteroposterior pelvic X-ray at postoperative $36^{\text {th }}$ month. 




Except the implant failure due to the motorcycle accident at the postoperative $23^{\text {rd }}$ month, no oncological (metastasis, recurrence) or local complications (infectious, mechanical) were observed till the final $36^{\text {th }}$ month follow-up (Figure 4c).

\section{DISCUSSION}

Chondrosarcoma is a malignant cartilaginous tumor seen primarily at adulthood. Chondrosarcomas in children and adolescents constitute $<5 \%$ of all cases. Secondary chondrosarcomas are nearly half of these cases in this age group. ${ }^{[1718]}$ Thus this case is remarkable because it was seen in the adolescent pelvic bone.

Surgical treatment of pelvic sarcomas is difficult due to its proximity to deep vascular and neurological structures. The type, grade, and extensivity of sarcoma are other difficulties in treatment. Moreover, the need for reconstruction of anatomical structures after surgery is a secondary problem to be solved. Various methods can be used for reconstruction after internal hemipelvectomy for limb-salvage surgery. ${ }^{[15]}$ These are massive allografts, autografts (recycling bone), arthrodeses, flail hip, saddle prostheses, acetabular cages, and $\mathrm{LUMiC}^{\circledR}$ etc. that can be used with proximal femur tumor prosthesis.

$\mathrm{LUMiC}^{\circledast}$ prosthesis was mostly used by implanting the remaining part of theiliac wing after Enneking type II periacetabular resection. At short-term follow-up, the LUMiC ${ }^{\circledR}$ prosthesis demonstrated low frequency of mechanical complications and failure. Therefore, this is a useful reconstruction for periacetabular resections for tumor or failed prior reconstructions. ${ }^{[15]}$ Infection and dislocation are relatively common complications in not only reconstruction by $\mathrm{LUMiC}^{\circledR}$ but also after other complex reconstructions (allografts, autografts, arthrodeses, saddle prostheses, acetabular cages etc.). ${ }^{[12-15]}$

In our case, despite the lack of adequate iliac bone stock after surgery, we used the LUMiC ${ }^{\circledR}$ prosthesis because of the young age and high bone quality of patient. There was no complication due to implant failure in postoperative follow-up until the motorcycle accident. According to this, $\mathrm{LUMiC}^{\circledast}$ can be used as a different technique in young patients with high bone quality, not only after type II resection, but also in type I+II resections in which the iliac wing is totally removed.

Furthermore, the MSTS scores of our case at the postoperative $6^{\text {th }}$ and $12^{\text {th }}$ months were $23(66 \%)$ and $29(83 \%)$, respectively. This suggests that $\mathrm{LUMiC}^{\circledR}$ has satisfactory functional results in patients whose extremity length is preserved when used with proximal femur tumor prosthesis.

In the case of implant failure as in our patient, there were options to strengthen the existing reconstruction or to perform flail hip which would result in shortness and not satisfy the patient functionally. We showed that LUMiC $^{\circledR}$ stability can be improved with screws and rods by using L5 vertebral corpus in patients who have insufficient bone stocks that develop implant failure due to trauma.

Similar cases can only be encountered in the form of case reports in the literature although not using the same technique. ${ }^{[17,19]}$ Therefore, this case is rare and unique for the literature in terms of an initial reconstruction technique as well as implant failure management strategy. 
Although no other complications were seen in our case, conducting multicenter studies that may increase the number of similar cases and comparisons with other techniques may contribute to the literature to obtain valid results in terms of possible complications and the success of this surgical technique.

\section{Declaration of conflicting interests}

The authors declared no conflicts of interest with respect to the authorship and/or publication of this article.

\section{Funding}

The authors received no financial support for the research and/or authorship of this article.

\section{REFERENCES}

1. Björnsson J, McLeod RA, Unni KK, Ilstrup DM, Pritchard DJ. Primary chondrosarcoma of long bones and limb girdles. Cancer 1998;83:2105-19.

2. Leddy LR, Holmes RE. Chondrosarcoma of bone. Cancer Treat Res 2014;162:117-30.

3. Pring ME, Weber KL, Unni KK, Sim FH. Chondrosarcoma of the pelvis. A review of sixty-four cases. J Bone Joint Surg [Am] 2001;83:1630-42.

4. Arnal-Burró J, Calvo-Haro JA, Igualada-Blazquez C, Gil-Martínez P, Cuervo-Dehesa M, Vaquero-Martín J. Hemipelvectomías tras sarcomas de localización pélvica de alto grado: pronóstico en condrosarcomas frente a otros tipos histológicos [Hemipelvectomy for the treatment of high-grade sarcomas: Pronostic of chondrosarcomas compared to other histological types]. Rev Esp Cir Ortop Traumatol 2016;60:67-74.

5. Enneking WF, Spanier SS, Goodman MA. A system for the surgical staging of musculoskeletal sarcoma. Clin Orthop Relat Res 1980;153:106-20.

6. Evans HL, Ayala AG, Romsdahl MM. Prognostic factors in chondrosarcoma of bone: a clinicopathologic analysis with emphasis on histologic grading. Cancer 1977;40:818-31.

7. Deloin X, Dumaine V, Biau D, Karoubi M, Babinet A, Tomeno B, et al. Pelvic chondrosarcomas: surgical treatment options. Orthop Traumatol Surg Res 2009;95:393-401.

8. Donati D, El Ghoneimy A, Bertoni F, Di Bella C, Mercuri M.
Surgical treatment and outcome of conventional pelvic chondrosarcoma. J Bone Joint Surg [Br] 2005;87:1527-30.

9. Atik OŞ. Which articles do we prefer to publish? Eklem Hastalik Cerrahisi 2018;29:1.

10. Bus MP, Szafranski A, Sellevold S, Goryn T, Jutte PC, Bramer JA, et al. LUMiC® Endoprosthetic Reconstruction After Periacetabular Tumor Resection: Short-term Results. Clin Orthop Relat Res 2017;475:686-95.

11. Moura DL, Fonseca R, Freitas J, Figueiredo A, Casanova J. Reconstruction with iliac pedestal cup and proximal femur tumor prosthesis after wide resection of chondrosarcoma - 10-year follow-up results. Rev Bras Ortop 2016;52:748-54.

12. Fisher NE, Patton JT, Grimer RJ, Porter D, Jeys L, Tillman $\mathrm{RM}$, et al. Ice-cream cone reconstruction of the pelvis: a new type of pelvic replacement: early results. J Bone Joint Surg [Br] 2011;93:684-8.

13. Enneking WF, Dunham WK. Resection and reconstruction for primary neoplasms involving the innominate bone. J Bone Joint Surg [Am] 1978;60:731-46.

14. Guzik G. The Use of LUMIC Prosthesis for the Treatment of Periacetabular Metastases. Ortop Traumatol Rehabil 2015;17:593-602.

15. Dominkus M, Darwish E, Funovics P. Reconstruction of the pelvis after resection of malignant bone tumours in children and adolescents. Recent Results Cancer Res 2009;179:85-111.

16. Enneking WF, Dunham W, Gebhardt MC, Malawar M, Pritchard DJ. A system for the functional evaluation of reconstructive procedures after surgical treatment of tumors of the musculoskeletal system. Clin Orthop Relat Res 1993;286:241-6.

17. Nystrom LM, DeYoung BR, Morcuende JA. Secondary chondrosarcoma of the pelvis arising from a solitary exostosis in an 11-year-old patient: a case report with 5-year follow-up. Iowa Orthop J 2013;33:213-6.

18. Puri A, Gulia A, Kurisunkal VJ, Sukumar V, Rekhi B. Chondrosarcomas in adolescents: are they different? J Pediatr Orthop B 2019.

19. Bekmez S, Ayvaz M, Mermerkaya MU, Tokgozoglu AM. Two-staged revision with custom made prosthesis in septic failure of massive allograft reconstruction after type II-III pelvic resection. Eklem Hastalik Cerrahisi 2014;25:182-5. 